\section{Where Has All the Nasal Polyposis Gone?}

Ortega-Martin $\mathrm{L}^{1 *}$, Betancor $\mathrm{D}^{1 *}$, Barroso $\mathrm{B}^{1}$, ValverdeMonge $\mathrm{M}^{1}$, Santillan $\mathrm{J}^{2}$, Villacampa $\mathrm{JM}^{2}$, Sastre $\mathrm{J}^{1,3}$

${ }^{1}$ Department of Allergy, Fundación Jiménez Díaz, Madrid, Spain ${ }^{2}$ Department of Otorhinolaryngology, Fundación Jiménez Díaz, Madrid, Spain

${ }^{3}$ Department of Medicine, Universidad Autónoma de Madrid, Madrid, Spain, CIBERES, Instituto de Salud Carlos III, Spain

*Contributed equally as first authors

J Investig Allergol Clin Immunol 2021; Vol. 31(6): 500-502 doi: 10.18176/jiaci.0679

Key words: Nasal polyps. Nasal polyposis. Eosinophils. Asthma. Nonsteroidal anti-inflammatory drug hypersensitivity.

Palabras clave: Pólipos nasales. Poliposis nasal. Eosinófilos. Asma. Hipersensibilidad a antiinflamatorios no esteroideos.

Nasal polyposis (NP) is a benign chronic inflammatory disease. However, it has a significant impact on quality of life (in particular, the loss of sense of smell), increases socioeconomic burden, and is associated with comorbidities [1]. The exact prevalence of chronic rhinosinusitis with NP (CRSwNP) in the general population is unknown [2]. The objective of this study was to describe the characteristics of patients with NP in a health district of Madrid, Spain.

At our university hospital, we performed a cross-sectional retrospective and observational study through a search of the electronic medical records of patients from our health district based on the terms nasal polyps or nasal polyposis for the years 2016, 2017, and 2018. We then confirmed that the patients selected had been diagnosed with nasal polyposis based on symptoms and nasal endoscopy [1]. We selected patients who had made at least 1 visit to the outpatient clinic (allergy and ear, nose, and throat [ENT] departments) during the study period. Data collected included patient demographics, presence of atopy based on positive skin test results to common aeroallergens, association with asthma and nonsteroidal anti-inflammatory drug hypersensitivity, use of health care resources such as computed tomography scans, visits/year, and treatment administered (both drugs and surgery). The polyp grading system used was that of Meltzer et al [3]. The Hospital Research Ethics Board approved the study. ENT specialists and allergologists participated in the study, since this condition is often comanaged by both.

Our health area includes 447600 inhabitants, of whom 393418 are aged $>18$ years. The initial search based on the terms used yielded a total of 667 individuals with a confirmed diagnosis of NP; we excluded 272 patients with a confirmed diagnosis of NP because they did not attend the ENT or allergy clinics during the years studied. Therefore, patients with NP in our electronic records accounted for $0.14 \%$ of the general population and $0.16 \%$ of the population aged $>18$ years

A total of 144 new patients fulfilled the criteria consecutively over the 3 years studied (59 in 2016, 53 in 2017, and 32 in 2018). The annual incidence of patients with NP attended in our tertiary hospital was 0.7 to 1.3 per $10000(0.013$ per 100 in 2016, 0.012 in 2017, and 0.007 in 2018).

The average age at diagnosis was 58.7 years (range, 23-96 years) with a higher prevalence of males (Table). Of 190 patients who underwent endonasal surgery, 66 (34\%) were grade 0 in the follow-up.

Other results are summarized in the Table. Although this study was not designed to calculate prevalence or annual incidence, data on NP managed at our tertiary hospital revealed a much lower prevalence of NP than reported in other studies [4-6]. Johansson et al [4] calculated a prevalence of $2.7 \%(95 \% \mathrm{CI}, 1.9-3.5)$ with an annual incidence of 1 to 20 per 1000 persons from a random sample of 1900 inhabitants aged $>20$ years in Sweden diagnosed by nasal endoscopy (compared with $0.07-0.13$ per 1000 in our study). A similar prevalence was found in a population in France screened using a validated questionnaire [5]. Our lower results could indicate that NP with minor symptoms and asymptomatic patients with NP do not visit their doctor, as shown by a study of 69 autopsies on patients who died of cardiopulmonary disease or cancer, where NP was found in $32 \%$ of autopsies and symptoms of NP were not reported in the medical records [6]. It is also possible that these patients were being managed by general practitioners.

Blood eosinophils in the present sample were relatively high (491.55 [327]), and $35 \%$ had $>500 / \mu \mathrm{L}$ eosinophils, which means that most had a T2 phenotype [7], as previously observed. As for age of diagnosis, male predominance, and comorbidities, the association with atopy (29\%), asthma $(45.32 \%)$ and hypersensitivity to NSAIDs $(13.16 \%)$ is consistent with that described in previous studies $[1-3,5]$. No cases of pediatric NP were diagnosed.

Remarkably, about half of the patients had undergone functional endoscopic endonasal surgery (FEES), and 51.05\% had undergone $>1$ FEES procedure. Of the 190 patients who had undergone $\geq 1$ FEES procedure, NP had recurred in $125(65.79 \%)$ at follow-up visits. Previous data show that about $40 \%$ of patients who underwent surgical polypectomy experience recurrences 18 months after surgery [8]; in a Spanish study with 10 years' follow-up, this figure was $22 \%$ [9]. In our study, we recorded a mean follow-up of 3.62 (5.79) years since the previous FEES; the fact that $56 \%$ of FEES patients had eosinophilia $(>500 / \mu \mathrm{L})$ could explain the higher recurrence, especially since blood eosinophilia has been associated with infiltration of nasal tissue by eosinophils [10]. 
Table. Demographic, Clinical, and Treatment Characteristics of Patients ( $N=395)$

\begin{tabular}{|c|c|c|c|}
\hline \multicolumn{2}{|l|}{ Epidemiologic data } & \multicolumn{2}{|l|}{ Treatments of nasal polyposis } \\
\hline Age, y, mean (SD) & $58.7(14.9)$ & First visit: & $9(278)$ \\
\hline Male sex, No. $(\%)$ & $234(59.24)$ & Nasal corticosteroids & $339(85)^{\mathrm{c}}$ \\
\hline Smoking habit, active smoking No. (\%) & $52(13.16)$ & FP nasal spray, No. (\%) & $141(36.7)$ \\
\hline Smoking habit, never smokers No. (\%) & $252(63.8)$ & $\begin{array}{l}\text { FF nasal spray, No. }(\%) \\
\text { MF nasal spray, No. }(\%)\end{array}$ & $\begin{array}{c}54(13.67) \\
144(36.45)\end{array}$ \\
\hline Asthma, No. (\%) & $179(45.32)$ & AH and FP nasal spray, No. (\%) & $12(3.04)$ \\
\hline Atopy, No. $(\%)^{\mathrm{a}}$ & $115(29.11)$ & $\begin{array}{l}\text { Oral corticosteroid bursts, No. (\%) } \\
\text { No of corticoid bursts, mean (SD) }\end{array}$ & $\begin{array}{c}160(40.50)^{\mathrm{c}} \\
1.82(1.39)\end{array}$ \\
\hline NSAID hypersensitivity, No. (\%) & $52(13.16)$ & Antibiotic pulses, No. (\%) & $49(12.41)$ \\
\hline \multicolumn{2}{|l|}{ Characteristics of Nasal Polyposis } & No. of antibiotic pulses, mean (SD) & $1.41(0.84)$ \\
\hline Polyps score first visit, mean (SD) & $2.55(1)$ & No treatment, No. $(\%)$ & $29(7.34)$ \\
\hline Polyps score last visit, mean (SD) & $1.45(1.34)$ & Nasal corticosteroids & $130(32)^{c}$ \\
\hline Sinus CT scan, mean (SD) & & FP nasal spray, No. (\%) & $46(11.65)$ \\
\hline Sinus CT scan, mean (SD) & $0.91(0.81)$ & FF nasal spray, No. (\%) & $16(4.05)$ \\
\hline Peripheral eosinophilia, No. $(\%)>500^{\mathrm{b}}$ & $138(34.94)$ & MF nasal spray, No. (\%) & $64(16.20)$ \\
\hline Eosinophils/ $\mu \mathrm{L}$, mean (SD) & $491.55(327.19)$ & AH and FP nasal spray, No. (\%) & $4(1.01)$ \\
\hline Eosinopnils/ $\mu \mathrm{L}$, mean (SD) & $491.55(321.19)$ & Oral corticosteroid bursts, No. (\%) & $62(15.70)^{\mathrm{c}}$ \\
\hline Polypectomy, No. (\%) & $190(48.10)$ & No. of corticosteroid bursts, mean (SD) & $1.90(2.83)$ \\
\hline Repeated polypectomy, No. (\%) & $97(51.05)$ & Antibiotic pulses, No. (\%) & $40(10.13)$ \\
\hline Number of polypectomies, mean (SD) & $1.3(0.88)$ & No. of antibiotic pulses, mean (SD) & $1.42(1)$ \\
\hline
\end{tabular}

Abbreviations: AH azelastine hydrochloride; FF, fluticasone furoate; FP, fluticasone propionate; MF, mometasone furoate; NSAID, nonsteroidal antiinflammatory drug.

aPositive skin prick test to $\geq 1$ usual aeroallergens.

${ }^{b}$ Eosinophilia is reported when eosinophils $\geq 500 / \mu \mathrm{L}$.

${ }^{c} P<.005$ between first and last visit.

As recommended, nasal corticosteroids were the first-line options in the patients we treated. Surprisingly, a significant number of patients abandoned this treatment during the study $(P<.05)$. This finding is in line with those of Guo et al [11], who found poor adherence to topical corticosteroids in patients with single recurrences of polyps after surgery, and may reflect a failure of medical care but not a failure of surgery. Interestingly, systemic corticosteroids were used in $40.50 \%$ of patients with a mean of 1.82 (1.39) pulses during followup. Although a significant decrease in corticosteroid bursts $(P<.05)$ was observed, many patients are still exposed to the potential adverse effects of systemic corticosteroids, as NP is a chronic disease. Despite all the treatments used, no significant difference in the polyp scores was observed between the first and last visits $(P=.77)$. The main weaknesses of this study are that it is retrospective and single-center.

We highlight that even though prevalence in the general population is approximately 1 and 20 per 1000 , most patients with NP do not need specialized care, probably because asymptomatic patients or those who have NP with minor symptoms are not searching for medical care or are not being referred to specialized clinics.

\section{Funding}

The authors declare that no funding was received for the present study.

\section{Conflicts of Interest}

J.S. reports having served as a consultant to Thermo Fisher, MEDA, Novartis, Sanofi, Leti, Faes Farma, Mundipharma, and GSK. He has also received lecture fees from Novartis, GSK, Stallergenes, Leti, and Faes Farma and grant support for research from Thermo Fisher, Sanofi, and ALK. The remaining authors declare that they have no conflicts of interest.

\section{References}

1. Fokkens WJ, Lund VJ, Hopkins C, Hellings PW, Kern R, Reitsma $\mathrm{S}$, et al. European Position Paper on Rhinosinusitis and Nasal Polyps 2020. Rhinology. 2020;58(20):1-464.

2. Khan A, Vandeplas G, Huynh T, Joish VN, Mannent L, Tomassen $P$, et al. The global allergy and asthma European network (GALEN) rhinosinusitis cohort: a large European crosssectional study of chronic rhinosinusitis patients with and without nasal polyps. Rhinology. 2019;57(1):32-42.

3. Meltzer EO, Hamilos DL, Hadley JA, Lanza DC, Marple BF, Nicklas RA, et al. Rhinosinusitis: developing guidance for clinical trials. J Allergy Clin Immunol. 2006;118(5 Suppl):S17-61.

4. Johansson L, Akerlund A, Holmberg K, Melén I, Bende M. Prevalence of nasal polyps in adults: the Skövde populationbased study. Ann Otol Rhinol Laryngol. 2003;112:625-9. 
5. Larsen PL, Tos M. Origin of nasal polyps: an endoscopic autopsy study. Laryngoscope. 2004;114:710-9.

6. Klossek JM, Neukirch F, Pribil C, Jankowski R, Serrano E, Chanal I, et al. Prevalence of nasal polyposis in France: a cross-sectional, case-control study. Allergy. 2005;60(2):2337.

7. Bachert C, Marple B, Hosemann W, Cavaliere C, Wen W, Zhang N. Endotypes of Chronic Rhinosinusitis with Nasal Polyps: Pathology and Possible Therapeutic Implications. J Allergy Clin Immunol Pract. 2020;8(5):1514-9.

8. DeConde AS, Mace JC, Levy JM, Rudmik L, Alt JA, Smith TL. Prevalence of polyp recurrence after endoscopic sinus surgery for chronic rhinosinusitis with nasal polyposis. Laryngoscope. 2017;127:550-5.

9. Lobo DR, López-Cortijo C, Laguna D, Pinilla M, Górriz C. Endoscopic sinonasal surgery: Review of 1,093 cases. Acta Otorrinolaringológica Española. 2003;54(6), 435-40.

10. Brescia G, Sfriso P, Marioni G. Role of inflammatory cells in chronic rhinosinusitis with nasal polyps. Acta OtoLaryngologica. 2019;139(1):48-51.

11. Guo M, Alasousi F, Okpaleke C, Habib AR, Javer A. Prognosis of Chronic Rhinosinusitis With Nasal Polyps Using Preoperative Eosinophil/Basophil Levels and Treatment Compliance. Am J Rhinol Allergy. 2018;32(5):440-6.

1 Manuscript received October 31, 2020; accepted for publication February 10, 2021.

Marcela Valverde-Monge

Allergy Department, University Hospital Fundación Jiménez

Avenida Reyes Católicos, 2

28040 Madrid, Spain

E-mail: marcela.valverde@quironsalud.es 